Article

\title{
Event and Community Development: Planning Legacy for the 2008 European Capital of Culture, Liverpool
}

\author{
Yi-De Liu \\ Graduate Institute of European Cultures and Tourism, National Taiwan Normal University, Taipei 106, Taiwan; \\ yideliu@ntnu.edu.tw; Tel.: +886-02-7734-3955
}

Received: 19 November 2017; Accepted: 6 December 2017; Published: 7 December 2017

\begin{abstract}
Event legacy has become a major topic of discussion in recent years. Especially, European Capital of Culture is emerging as a means of facilitating community development in Europe. Based on a case study of the 2008 European Capital of Culture Liverpool, this article aims to conceptualise the relationship between an event and its sustained effects on community development. Methodologically, adopting case study as approach, both primary and secondary were collected and analysed, including four times neighborhood surveys, official evaluation reports and academic publications. The study period is from 2007 to 2015 to monitor changes in an event's impacts. The results reveal four dimensions of effects, including: cultural access and engagement, volunteering, governance and infrastructure, and sense of place. Overall, the study stresses the importance of integrating the event into a long-term development strategy of the city, through synergies between culture and urban regeneration and community renewal.
\end{abstract}

Keywords: event; legacy; community development; European Capital of Culture; Liverpool

\section{Introduction}

The legacy of a major event has become a major topic of discussion in recent years. For example, Edizel [1] argued that community development and legacy planning have become essential components of urban regeneration since the early 2000s. However, most of the time, the temporal nature of the event is recognized as a special challenge [2]. Kaplanidou and Karadakis [3] argued that the improvement of the host city could be guaranteed only if a long-term legacy plan is considered during the planning phase. In the academic field, there was therefore a paradigm shift-from the studies on the impacts of the event towards the assessment of the event's legacy. The legacy of event has also gone from an unknown outcome to something that should be planned from the outset [1].

Among many reasons why cities bid to organise major events, an improvement on local community is one of the considerations. Local residents in the host city are not only the main audience, but also a vital source of sustainability for events [1,4,5]. For example, Richards and Palmer [5] argued that "if events can ensure that all residents can meet their cultural needs in an equitable manner while enhancing residents' sense of belonging, they should be socially viable". Doherty [6] illustrated how major events can bring vitality to a community. There can be considerable economic benefits from visitor spending, increasing the community profile and creating jobs. A community can also benefit from infrastructure development when there are new or improved facilities. Gratton and Taylor [7] and Crompton [8] also emphasized that social benefit for a community could be built up, such as enhancing community pride or enhancing social inclusion.

The European Capital of Culture (hereinafter ECOC) has emerged as a means of facilitating community development in Europe. The ECOC program was launched in 1985 and ECOC has been awarded to nearly 60 cities in 30 countries. According to Palmer-Rae [4], the ECOC program is probably 
one of the most successful cultural initiatives launched by the European Union. The origin of the ECOC was purely cultural; however, as it developed, the cities used it in different ways. Extensive research has been done to explore the immediate impacts of hosting ECOC events; however, few studies attempt to assess the legacy of ECOC and its contribution to community development. Based on a case study of Liverpool as the 2008 ECOC, this article aims to conceptualise the linkage between ECOC and its sustained effects on community development. Two central issues were raised and addressed in this study: (1) what are the discernable long-term effects of ECOC status in terms of community development? and (2) how can we plan and achieve this desired legacy? The following section will provide a review of the literature on the notions of event legacy and community development, as well as their articulations. Methodologically, this study offers a semi-longitudinal perspective, and is based on a combination of primary and secondary data. The result section breaks down the findings into four categories: cultural access and engagement, volunteering, governance and infrastructure, and sense of place. The paper concludes by expanding the findings of this case study to the theoretical literature.

\section{Literature Review}

\subsection{Event Legacy and ECOC}

Several scholars, such as Preuss [9], Gratton and Preuss [10], and Cashman [11], have tried to define the notion of legacy. For instance, according to Preuss [9], "legacy is all planned and unplanned, the positive and negative, tangible and intangible structures created for and by a cultural event that remains longer than the event itself" (p. 121). In this sense, unlike "impact" which is caused by a short-term impetus, "legacy" can only be achieved if an event has changed the structure of a city as a whole. Since the legacy of an event can provide a justification of public spending and obtain community support [12], it has become central to the decision to host an event [13], and contribute to community development [14].

The literature on events presents several classifications of legacies. First, hard legacy (also known as tangible legacy, such as visitor impacts, buildings, new organizations and projects) and soft legacy (or intangible legacy, such as image enhancement, increased confidence, personal skills and the acquisition of new ideas) are fundamental to existing discussions (e.g., [3,9,15]). The hard or tangible legacy is easily measured and, therefore, attracts more attention. On the other hand, soft or intangible legacy is less studied because of its complexity and its difficulty of quantification and measurement [16]. Kaplanidou [17] believed that tangible legacy does not necessarily affect local populations, and intangible results might be recalled at any point during the everyday life. Apart from the dichotomous classifications mentioned above, multidimensional approaches have also been adopted to differentiate between different forms of the inheritance. For example, Cashman [11] identified six fields of legacies: economics; infrastructure, public life, education, politics and culture.

In the early stages of the ECOC program, practical plans for the legacy were not widespread throughout the year. However, since Decision 1622/2006/EC, the explicit requirement that the ECOC is sustainable and has a long-term impact has led to a clearer awareness and commitment to legacy planning of some ECOC cities. In some cases, cities have sought to promote sustainability by making it a criterion in the choice of activities for the host year. However, the question of ensuring legacy is complex for the ECOC host cities. The major reason is that legacy has to be planned, budgeted and worked [2]. Many ECOCs have experienced financial problems for long-term planning, such as inadequate funding or reduced sponsorship [4]. Other difficulties were lack of advanced planning or long-term vision. As such, evidence of successful legacy planning is still limited for the ECOC cities.

\subsection{Event and Community Development}

Hosting events claims to bring several benefits not only to personal development at the individual level, but also to the host communities as a whole. In this study, community development is defined as 
how community can be strengthened and sustained through an event, including the improvement in cultural access and engagement, volunteering, governance and infrastructure, as well as sense of place.

Cultural Access and Engagement: A main approach of sustainable events is to improve accessibility to event projects and programs for the local residents [5]. For many ECOC cities, socio-economic problems are the result of post-industrial restructuring, so wider social goals are often assigned to event programs, such as achieving community development and social inclusion [4]. Access development can be undertaken in many ways by ECOC cities, but almost all ECOC cities have included at least some programs to improve accessibility of events, such as reaching local minority groups or linking community initiatives to traditional event programs [4]. On the other hand, Matarasso [18] highlighted many ways in which cultural participation can contribute to community development, including increased trust, self-esteem, skills and social atmosphere. Michalos [19] also argued that participation in cultural and artistic activities enhances the overall satisfaction of life. Consequently, increasing the level of participation and interest in culture is an important target for many ECOC cities [4].

Volunteering: Hosting major events provides a chance for community development through volunteer work [20]. The legacy of volunteering in a community can be indicated by increased voluntary support for other special events in the community and increased volunteering in the community at large [6]. According to Kwok et al. [21], a considerable number of studies have confirmed the positive effects of volunteering, such as a growing sense of life satisfaction or a perceived improvement in the quality of life.

Governance and Infrastructure: Major event, in general, is only part of the long process of urban development. As suggested by Evans [22] (p. 6), "an event alone is rarely enough to raise or sustain investment in regeneration to achieve competitive status of city or cultural city and the social and economic benefits pursued." Events can be an incentive to develop new infrastructure or accelerate the completion of existing projects that would either take years to complete or never have been completed in the host city [23]. The new infrastructure provided to the city benefits not only tourists but also the quality of life of the inhabitants [3].

Sense of Place: Derrett [24] argued that events could contribute to enhancing civic pride and confidence, especially when local people have held an event. Richards and Palmer [5] (p. 418) also noted that "the sense of community is one of the key elements of the distinctiveness of cities, and cultural events can be an important means of supporting a sense of belonging and a local pride". As such, an essential aspect of the social legacy of an event is the betterment of residents' self-image, and then contributing to improving the sense of community and local identity [25].

\section{Methods}

For the purposes of this study, the community development legacy is defined as the long-term impacts that the 2008 ECOC could contribute to the socio-cultural legacies of Liverpool's local communities, including cultural access and commitment, volunteering, governance and infrastructure and sense of place. The research themes are answered by drawing on the literature of various disciplines in order to conceptualize the synergy of the impacts of the event on community development. Second, longitudinal and multi-faceted data, primary and secondary, were collected and analysed. The study period is from 2007 to 2015 in order to monitor changes in performance. Specifically, the data come from the following four types of sources.

(1) Author's primary research: following the neighbourhood surveys of the Impacts 08 research program in 2007, 2008 and 2009, the author conducted the fourth neighbourhood survey in 2015 to understand how residents of Liverpool evaluate the outcome of the legacies of their overall quality of life. Four neighbourhoods representing geographic and demographic variations of the population were selected and data were collected from 592 residents.

(2) Evaluation reports of the 2008 ECOC Liverpool: Commissioned by Liverpool City Council, a joint research initiative called 'Impacts 08 ' was conducted by the two universities in Liverpool. 
Impacts 08 evaluated, from 2005 to 2009, the social, cultural and economic effects of Liverpool's hosting the ECOC title in 2008, and yielded a series of official evaluation reports. The data of this research is mainly derived from the neighbourhood survey [26] and the volunteer survey [27].

(3) Evaluation reports of the ECOC programme as a whole. In order to extend the breadth of analysis, the author referred also to the following three evaluation reports of the ECOC programme as a whole.

- Palmer/Rae report [4]: A research project, with funding of the European Commission, was conducted by Palmer-Rae Associates. It covers the 1995 to 2004 ECOC hosts and provides a comparative perspective of the impacts of ECOC on different cities/regions.

- Ecorys report [28]: Commissioned by the European Commission, Ecorys—an economic research and consulting company-took charge of collecting data, both quantitative and qualitative, and yielded an ex-post evaluation report for each of the ECOC host cities since 2007.

- Entitled as "European Capitals of Culture: success strategies and long-term effects" is a recent study conducted by García and Cox [2] for the European Parliament. After over 28 years in development, this report aims at assessing the long-term effects of hosting the ECOC Programme, and exploring the strategies for success and 'best practices'.

(4) Academic publications: During the past eight years, several refereed journals and book chapters were dedicated to explore the lessons from Liverpool as the 2008 ECOC Liverpool. These academic publications provide a basis for validating and complementing the findings of the above official documents.

\section{Results}

\subsection{Access and Engagement}

Throughout the program, Liverpool emphasised the role of the ECOC title in expanding access to culture and its commitment, as well as the potential role of culture in social cohesion and community development. Liverpool attempted to address access and inclusion issues by developing two major programs in the city's outlying and private neighbourhoods-Creative Communities and the Four Corners neighbourhood program [2,28]. The Creative Communities program was regarded as the largest public and community arts program in Europe, receiving \$11 million in four-year funding and involving 160,000 participants, including all schools in Liverpool. The Four Corners program, involving 27,000 people, aims to use art to explore community life [28]. Liverpool has also sought to involve schoolchildren in the city as part of their Creative Learning Networks program in order to maximise creative and cultural education opportunities and develop a curriculum for collaborative teaching and learning with creativity [2].

As a result, all students in the city participated in at least one activity during the year [29]. The City 21 planning project also involved 160 schools, 21 creative collaborators and 8000 participants [28]. In addition to efforts to maximize accessibility, ECOC Liverpool also aims to encourage more people to participate in cultural activities and to increase the cultural interests of residents, thereby improving the legacy of the event. To boost participation in the population as a whole, Liverpool has created a dedicated organization-the Liverpool Culture Company-responsible for coordinating a program of brand events over eight thematic years. As a result, the ECOC program in Liverpool held more than 7000 activities in 2008 and more than 41,000 activities over four years (2005-2008) [30]. In addition, as a result of the implementation of extensive community arts programs covering all districts of the city and including all schools, the ECOC reinforced the cultural vitality of the city and resulted in an important cultural legacy.

The impacts of the above initiatives were highlighted by the neighbourhood survey conducted in 2007, 2009 and 2015. For the question of accessibility, the percentage of respondents who agreed that "the ECOC will not be ordinary people" decreased from $37 \%$ to $21 \%$, and only "the city centre 
benefited from ECOC" decreased from $66 \%$ in 2007 to $56 \%$ in 2009 [26]. However, the major criticism remained the focus and concentration of events in the city centre and the lack of activities in the suburbs. Regarding cultural participation, $66 \%$ of Liverpool residents participated in at least one ECOC event in 2008 and $14 \%$ also tried new cultural activities such as visiting a cultural venue or attending another type of event. In addition, the ECOC has played a catalytic role in increasing cultural interest. The ECOC attracted more than $37 \%$ of respondents in cultural activities.

These suggest that there has been a steady increase in the number of people who feel there are benefits from the ECOC outside of Liverpool's downtown and that the ECOC has changed the attitude of residents towards culture. Although there has been good engagement in the ECOC across the city, a lower level of cultural participation has been found in some disadvantaged communities, attributing both the lower cultural capital resulting from the socio-economic status, as well as the distances and travel costs [31,32]. From a longer-term perspective, according to the 2015 survey, "cultural engagement" was ranked 2nd among the five legacy dimensions as the most important legacy of ECOC 2008 [33]. This shows that the access of peripheral and socially disadvantaged geographical communities to cultural activities has also been improved.

\subsection{Volunteering}

Liverpool was one of the cities of the ECOC to actively engage and largely voluntary. The city intends to use volunteer programs to provide concrete examples of how to use culture to support community engagement and to foster understanding and dialogue on key social issues [34]. The Liverpool Volunteer Program 08 was a key element in the 08 Welcome program. The 08 Welcome program was created by the Liverpool Culture Company in 2005 to provide customer service improvements through 2008. Participants in the 08 Volunteer program joined a wide range of activities to provide better customer service from 2005 to 2008. Overall, 4082 volunteers enrolled in the program, of which 851 completed the training process and became active volunteers. They participated in 150 events and volunteered 6974 days during the period 2005-2008 [2,28]. The volunteer program also used volunteerism as a means of engaging people from more disadvantaged communities in order to build confidence, acquire skills [30] and be a city host [34]. When 2008 ECOC came to the end, the program of volunteers continued in 2009. Liverpool City Council also developed a range of options for the future use of volunteers, which could lead to a greater variety of opportunities available for volunteers to support community activity [27].

Regarding the results of a 08 Volunteer, the voluntary survey reported a series of social and cultural impacts of participation [27]. Questioned in 2009, the survey responses identified four key impacts of volunteering: (1) meeting people; (2) pride in the city; (3) learning and skills; and (4) building trust. Specifically, being a volunteer gave people the opportunity to meet people and make connections and friendships. Participating in the events program and making a positive contribution to improving Liverpool's external perceptions has strengthened their own pride in the city. Volunteering has also seen a number of more tangible results as a result of their involvement. Volunteers have greatly increased their knowledge of Liverpool's history, heritage and cultural offer, and have developed their confidence and the skills needed to deal with members of the public. In quantitative terms, $45 \%$ of respondents felt they "contributed to the local community" and 65\% "showed visitors how great Liverpool is".

\subsection{Governance and Infrastructure}

In order to support long-term impacts of an event, there is a need for mechanisms, such as an operational unit, monitoring programs, infrastructure and financial support, etc. Following 2008, the team responsible for the dissemination of future cultural programming is called Culture Liverpool and operates within the City Council. A cultural strategy has also been developed to ensure the legacy of the ECOC year and the continuation of the major program of events. In addition, Liverpool City Council has committed to supporting increased funding for culture for two more years, and some 
activities that started in 2008 have been retained beyond the year of the title, such as the creative education program [28].

On the other hand, the Liverpool ECOC was seen as a crucial trigger for parallel physical regeneration of the city [35]. Jones and Wilks-Heeg [36] argued that the ECOC title became a catalyst for new public and private investment, and the projects involved in the redevelopment of the Liverpool centre have grown in importance and urgency. The ECOC status has been used very effectively to focus on the completion of existing projects, including Liverpool's first major concert/conference venue-Echo Arena and the refurbishment of Bluecoat Arts Centre. Combined with the new Liverpool Museum, an indirect legacy of the ECOC year will undoubtedly be an improved cultural offer for Liverpool [28].

Data from the 2007 and 2009 neighbourhood surveys revealed that residents ranked "regeneration" as the 1st in the ECOC's "best things" list. This suggested that residents both appreciated the downtown regeneration and saw the improvement in the amount, scope and quality of recreational provisions following ECOC [27]. Later, the 2015 neighbourhood survey revealed that "the legacy of infrastructure and amenities" was ranked as ECOC's 3rd most important legacy. It refers to improving the infrastructure and cultural provision associated with an event, including cultural facilities/space and events/activities [33].

\subsection{Sense of Place}

Throughout the program, Liverpool highlighted the potential role of the ECOC in building a sense of community. The above-mentioned community development initiatives, including the Creative Communities, Four Corners and the 08 Volunteer programs, have all attempted to engage the local community in the city's cultural life and, in turn, the support of the local community. It was achieved by encouraging disadvantaged communities to participate in projects that enable them to represent the city and thus become active agents in the production of the image of the city [37].

As a result, the neighbourhood survey in 2007 and 2009 [27] revealed that the majority of respondents agreed that the city is much better after the ECOC, although the difference was not significant. There was also growing confidence in external perceptions. People felt that the view of Liverpool owned by people outside the city has improved as a result of ECOC. However, greater scepticism existed with the direct impact of ECOC on the individual community. The disadvantaged communities were less likely to agree with the impacts on sense of community than those advantaged communities-a problem likely related to an event's accessibility. From a longer-term perspective, according to the 2015 survey, "image of the city" and "sense of community" were ranked as 1st and 4th important bequests among the 5 dimensions [33]. The results of the survey reiterated that the ECOC's designation and activities have helped to enhance the city's external image and encouraged residents to believe that the city is viewed positively outside the city in the long term. However, improving community awareness at the individual level was less considered as the major legacy of ECOC 2008.

\section{Conclusions}

In recent years, increasing attention has been given to the socio-cultural impacts of major events. However, community development and social inclusion are weak components of this event-led strategy of urban regeneration. This study helped to fill this gap by focusing on an event's impacts of community development in Liverpool. However, it is important to be aware of the limitations of this research. To convey the value behind the results, this research provides the following suggestions, as well as challenges, for cities attempting to adopt an event-led strategy for community development.

Liverpool is one of the few cities, which considered the legacy before organising the ECOC, and a major vision was to leave a legacy for the benefit of the local community. To realise the spirit of cultural democracy and reduce the barriers of participation, Liverpool has treated the development of access as a political guideline and adopted many measures. In order to improve access to culture, meet the needs of different groups and generate community enthusiasm, an eight-year thematic program of 
events has been created, combined with a series of community Creative Communities, Four Comers, 08 Welcome and 08 Volunteer programs to stimulate participation in the broader population. Different methods exist to encourage participation in ECOC. Liverpool's lessons have shown that the use of public space (open-air events), free of charge, mass audiences and initiatives to help people participate in cultural programs are effective ways to increase self-accessibility and participation. To support the legacy of 2008, Liverpool continues to hold free street events to include all cultural and ethnic groups in the city.

The ECOC also played a catalytic role in increasing cultural interest, wider cultural participation and volunteering. This shows that the implementation of community participation strategies is a prerequisite for improving social and cultural legacies of a major event. With regard to volunteering, research indicates that volunteer participation in events, visits to other cultural facilities, and interest in cultural activities are all improved at some level. In addition, volunteering has contributed to the nutrition of social capital, such as personal networks, skills upgrading and civic pride. However, as Willems-Braun [38] suggested, participation in events, like other forms of cultural activities, is often limited to specific groups. In other words, the inclusion of a group often involves the exclusion of others. The task of increasing participation in events and accessibility is therefore not without its difficulties. The results reveal that a considerable gap has been detected between the privileged and disadvantaged Liverpool communities as part of the cultural commitment, due to their geographical location. Centralized cultural facilities and programs reflect the fact that proximity to the city centre is crucial to cultural engagement.

The planning legacy for the event must take into account its ad hoc nature and some activities cannot continue. It is therefore necessary to examine not only whether programs are supported, but also the effects on governance and long-term infrastructure improvements [4]. One of the keys to Liverpool's success has been the integration of the event as part of a long-term cultural development strategy, and synergies between culture and other areas, such as urban regeneration, community development and education, etc. To have a lasting legacy, Liverpool has tried as much as possible to integrate the event with other planned and long-term developments in the city. Finally, Liverpool suffered serious social problems caused by the economic recession and therefore considered the ECOC as an opportunity to improve the sense of place. In general, there was a growing confidence in the city's self-image and external perceptions. However, scepticism remained with the impacts of ECOC on the individual community, so a lower level of community sense was found.

Acknowledgments: I would like to thank the Ministry of Science and Technology of Taiwan for the grant, numbered MOST 105-2410-H-003-066-MY2.

Conflicts of Interest: The author declares no conflict of interest.

\section{References}

1. Edizel, H.Ö. Governance of Sustainable Event-Led Regeneration: The Case of London 2012 Olympics. Ph.D. Thesis, Brunel University, London, UK, 2014.

2. García, B.; Cox, T. European Capitals of Culture: Success Strategies and Long-Term Effects; Publications Office of the European Union: Luxembourg, 2013.

3. Kaplanidou, K.; Karadakis, K. Understanding the legacies of a host Olympic city: The case of the 2010 Vancouver Olympic Games. Sport Mark. Q. 2010, 19, 110-117.

4. Palmer-Rae. European Cities and Capitals of Culture: Study Prepared for the European Commission, Part 1; Palmer-Rae Associates: Brussels, Belgium, 2004.

5. Richards, G.; Palmer, R. Eventful Cities: Cultural Management and Urban Revitalization; ButterworthHeinemann: Amsterdam, The Netherlands, 2010.

6. Doherty, A. The volunteer legacy of a major sport event. J. Policy Res. Tour. Leis. Events 2009, 1, $185-207$. [CrossRef]

7. Gratton, C.; Taylor, P. Economics of Sports and Recreation; Taylor \& Francis: London, UK, 2000. 
8. Crompton, J. Beyond economic impact: An alternative rationale for the public subsidy of major league sports facilities. J. Sport Manag. 2004, 18, 40-58. [CrossRef]

9. Preuss, H. The conceptualisation and measurement of mega sport event legacies. J. Sport Tour. 2007, 12, 207-228. [CrossRef]

10. Gratton, C.; Preuss, H. Maximizing Olympic impacts by building up legacies. Int. J. Hist. Sport 2008, 25, 1922-1938. [CrossRef]

11. Cashman, R. The Bitter-Sweet Awakening: The Legacy of the Sydney 2000 Olympic Games; Walla Walla Press: Sydney, Australia, 2006.

12. Matheson, C.M. Legacy planning, regeneration and events: The Glasgow 2014 Commonwealth Games. Local Econ. 2010, 25, 10-23. [CrossRef]

13. Allen, J.; O’Toole, W.; Harris, R.; McDonnell, I. Festival and Special Event Management, 4th ed.; John Wiley \& Sons: Milton, Australia, 2008.

14. Pacione, M. The role of events in urban regeneration. In Routledge Handbook of Events; Page, S.J., Connell, J., Eds.; Routledge: London, UK, 2012; pp. 385-400.

15. Kaplanidou, K.; Karadakis, K.; Gibson, H.; Thapa, B.; Walker, M.; Geldenhuys, S.; Coetzee, W. Quality of life, event impacts, and mega-event support among South African residents before and after the 2010 FIFA world cup. J. Travel Res. 2013, 52, 631-645. [CrossRef]

16. Ferrari, S.; Guala, C. Mega-events and their legacy: Image and tourism in Genoa, Turin and Milan. Leis. Stud. 2017, 36, 119-137. [CrossRef]

17. Kaplanidou, K. The importance of legacy outcomes for Olympic Games four summer host cities residents' quality of life: 1996-2008. Eur. Sport Manag. Q. 2012, 12, 397-433. [CrossRef]

18. Matarasso, F. Use or Ornament? The Social Impact of Participation in the Arts; Comedia: Stroud, UK, 1997.

19. Michalos, A.C. Arts and the quality of life: An exploratory study. Soc. Indic. Res. 2005, 71, 11-59. [CrossRef]

20. Downward, P.; Ralston, R. The sports development potential of sports event volunteering: Insights from the XVII Manchester Commonwealth Games. Eur. Sport Manag. Q. 2006, 6, 333-351. [CrossRef]

21. Kwok, Y.Y.; Chui, W.H.; Wong, L.P. Need satisfaction mechanism linking volunteer motivation and life satisfaction: A mediation study of volunteers subjective well-being. Soc. Indic. Res. 2013, 114, 1315-1329. [CrossRef]

22. Evans, G.L. Cities of Culture and the regeneration game. Lond. J. Tour. Sport Creat. Ind. 2011, 5, 5-18.

23. Smith, A. Events and Urban Regeneration: The Strategic Use of Events to Revitalise Cities; Routledge: London, UK, 2012.

24. Derrett, R. Making sense of how festivals demonstrate a community's sense of place. Event Manag. 2003, 8, 49-58. [CrossRef]

25. García, B. Cultural policy and urban regeneration in Western European Cities. Local Econ. 2004, 19, 312-326. [CrossRef]

26. Impacts 08. Neighbourhood Impacts: A Longitudinal Research Study into the Impact of the Liverpool European Capital of Culture on Local Residents; Impacts 08: Liverpool, UK, 2010.

27. Impacts 08. Volunteering for Culture: Exploring the Impact of Being a 08 Volunteer; Impacts 08: Liverpool, UK, 2010.

28. Ecorys. Ex-Post Evaluation of 2007 E 2008 European Capitals of Culture: Final Report; Ecorys: Birmingham, UK, 2009.

29. European Union. European Capitals of Culture 30 Years; Publications Office of the European Union: Luxembourg, 2015.

30. Impacts 08. Creating an Impact: Liverpool's Experience as European Capital of Culture; Impacts 08: Liverpool, UK, 2010.

31. Liu, Y.D. Socio-cultural impacts of major event: Evidence from the 2008 European Capital of Culture, Liverpool. Soc. Indic. Res. 2014, 115, 983-998. [CrossRef]

32. Liu, Y.D. Event and quality of life: A case study of Liverpool as the 2008 European Capital of Culture. Appl. Res. Qual. Life 2016, 11, 707-721. [CrossRef]

33. Liu, Y.D. Quality of life as event legacy: An evaluation of Liverpool as the 2008 European Capital of Culture. Appl. Res. Qual. Life 2017, 12, 653-670. [CrossRef]

34. European Communities. European Capitals of Culture: The Road to Success from 1985 to 2010; Publications Office of the European Communities: Luxembourg, 2009. 
35. Cox, T.; O’Brien, D. The "scouse wedding" and other myths: Reflections on the evolution of a "Liverpool model" for culture-led urban regeneration. Cult. Trends 2012, 21, 93-101. [CrossRef]

36. Jones, P.; Wilks-Heeg, S. Capitalising culture: Liverpool 2008. Local Econ. 2004, 19, 341-360. [CrossRef]

37. Kokosalakis, C.; Bagnall, G.; Selby, M.; Burns, S. Place image and urban regeneration in Liverpool. Int. J. Consum. Stud. 2006, 30, 389-397. [CrossRef]

38. Willems-Braun, B. Situating cultural politics: Fringe festivals and the production of spaces of intersubjectivity. Environ. Plan. D 1994, 12, 75-104. [CrossRef]

(c) 2017 by the author. Licensee MDPI, Basel, Switzerland. This article is an open access article distributed under the terms and conditions of the Creative Commons Attribution (CC BY) license (http:/ / creativecommons.org/licenses/by/4.0/). 